\title{
Habitar la imagen. En busca de lo micro-inmanente por medio de la poética
}

\author{
Martin Kanek Gutiérrez \\ UNIMINUTO-Colombia \\ mkgv13@gmail.com
}

\author{
Jeannette Plaza Zúñiga \\ UNIMINUTO-Colombia \\ jplazazuniga@gmail.com
}

\author{
Catalina Campuzano \\ UNIMINUTO-Colombia \\ ccampuzanno@gmail.com
}

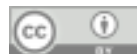

Artículo bajo licencia Creative Commons Atribución 4.0 Internacional (CC BY 4.0) ENVIADO: 20-12-09 ACEPTADO: 20-12-29

\section{RESUMEN}

Se plantea que el Habitar la imagen comprende la relación mediada por lo visual entre lo interno y externo del ser, acción en cual la memoria y la interpretación de la imagen son los medios que permiten asignar significado a la experiencia del individuo, en la que los objetos adquieren sentido para el sujeto. Desde el enfoque de la fenomenología de la percepción se entiende a la imagen desde lo micro-inmanente a través de tres tipos: imágenes-mundo, imágenesvivientes e imágenes-ontológicas, en cuya interrelación se manifiesta la existencia en medio de la influencia del espacio-tiempo habitado.

PALABRAs CLAVE

fenomenología, subjetividad, análisis visual, tipos de imagen, memoria.

\section{RESUMO}

Sugere-se que o Habitar a imagem compreende a relação mediada pelo visual entre o interno e o externo do ser, ação em que a memória e a interpretação da imagem são os meios que permitem atribuir sentido à experiência do indivíduo, em que o objetos fazem sentido para o sujeito. Na perspectiva da fenomenologia da percepção, a imagem é compreendida desde o micro-imanente por meio de três tipos: imagens-mundo, imagensvivas e imagens-ontológicas, em cuja inter-relação a existência se manifesta em meio à influência do espaço-tempo habitado.

\section{PALAVRAS-CHAVE}

fenomenologia, subjetividade, análise visual, tipos de imagem, memória.

\section{ABSTRACT}

It is suggested that inhabiting the image comprises the relationship mediated by the visual between the internal and external of the being, an action in which memory and the interpretation of the image are the means that allow assigning meaning to the experience of the individual, in which the objects make sense to the subject. From the perspective of the phenomenology of perception, the image is understood from the micro-immanent through three types: world-images, living-images, and ontological-images, in whose interrelation existence is manifested amid the influence of the inhabited space-time.

\section{KEYWORDS}

phenomenology, subjectivity, visual analysis, types of image, memory. 
Dormido en el caballo, luna lejana, ensueño prolongado: humo de hogares donde hierve té. Matsuo Basho

\section{INTRODUCCIÓN}

El presente artículo es resultado de la investigación denominada Habitantes de imágenes: una investigación poética entre la imagen audiovisual y la subjetividad, como parte de la labor del grupo Complejidades históricas de la comunicación y el diseño en Colombia. El interés del grupo se centra en develar sistemas históricos-hermanéuticos a través de las historias de vida de sujetos que no están alineados a una visión institucionalizada de la historia. El proyecto Habitantes de Imágenes se enfocó en la realización de entrevistas, la interpretación de dibujos y planteamientos teóricos, con intencionados deslices poéticos para aproximarnos al arte, buscando entender las relaciones existentes y emergentes entre el sujeto y la imagen, entre el individuo y lo audiovisual. Se propuso para este estudio trabajar con tres sujetos: un técnico de reparación de televisores, un artista dedicado a la realización de videos y un youtuber. En dos años del proceso de investigación se realizaron entrevistas a los dos primeros, y el tercero fue modificado y reemplazado por el propio investigador para tener en cuenta su experiencia. Se quiso ir más allá de la faceta emocional y epistémica de la representación para ahondar en la identificación de la imagen como vínculo entre lo interno y lo externo del ser humano, visto a través de algunas posturas teóricas en las que se intenta interpretar la relación entre el artista visual y la imagen.

En el proceso ha surgido una pregunta de gran importancia: ¿qué es un habitante de imágenes? Este concepto nació de un ejercicio poético espontáneo ya que se imaginó cómo diferentes sujetos habitan imágenes audiovisuales. Actualmente podemos ver cómo ésta figura poética se manifiesta en lo cotidiano al ser una actividad que se puede referir como parte de nuestra realidad social. Nuestro entorno está lleno de pantallas que reproducen permanentemente imágenes audiovisuales en restaurantes, espacios públicos, los videos-selfies por medio de las redes sociales, y la pantalla misma en la que se ha escrito este texto. Actualmente habitamos con imágenes audiovisuales como parte de nuestra cotidianidad. En este sentido Márquez expresa en su libro Una genealogía de la pantalla: "Vivimos rodeado de pantallas. En casa, en calles, en trabajos, en metros, en aviones, en bares, en tiendas, en centros comerciales. Las pantallas forman una parte indispensable de nuestra vida cotidiana. No podemos vivir sin ellas" (2015: 9).

Pareciera que todos somos de algún modo habitantes de imágenes. Se tendría que diferenciar a quienes son los sujetos parte del presente estudio y a las demás personas. Se han seleccionado a personas que por su carácter creativo se relacionan de forma cotidiana con las imágenes. El artista del video tiene la creatividad para registrar imágenes y contar algo desde su perspectiva. En el caso del investigador indaga de manera reflexiva en las imágenes que consume a lo largo de su vida, lo que le lleva a habitar la imagen en momentos determinados.

Partiendo de un enfoque fenomenológico se propuso en un inicio que el sujeto integra aquello que ve, por lo cual habita la imagen. El consumismo informativo visual es unidireccional, se convierte en un bucle, un "ouroboros mediático" (Gutiérrez, 2017: 110). La imagen pasa de ser un conjunto de datos agrupados en bits a entenderse como la experiencia que da unidad al sujeto y la imagen emitida/percibida. Se presenta en el siguiente diagrama el concepto de "ouroboros mediático" que concibe lo lineal de manera torcida, permitiendo que regrese o retorne al sujeto hacia lo emitido (ver Figura. 1). La emoción-experiencia 
surge en este tránsito como manifestación de la subjetividad del ser humano. Así podemos ver la imagen como acontecimiento que une en la distancia al que ve con lo que es visto, cohesionando, logrando que lo interno y externo se toquen en el punto mismo donde se da la experiencia.

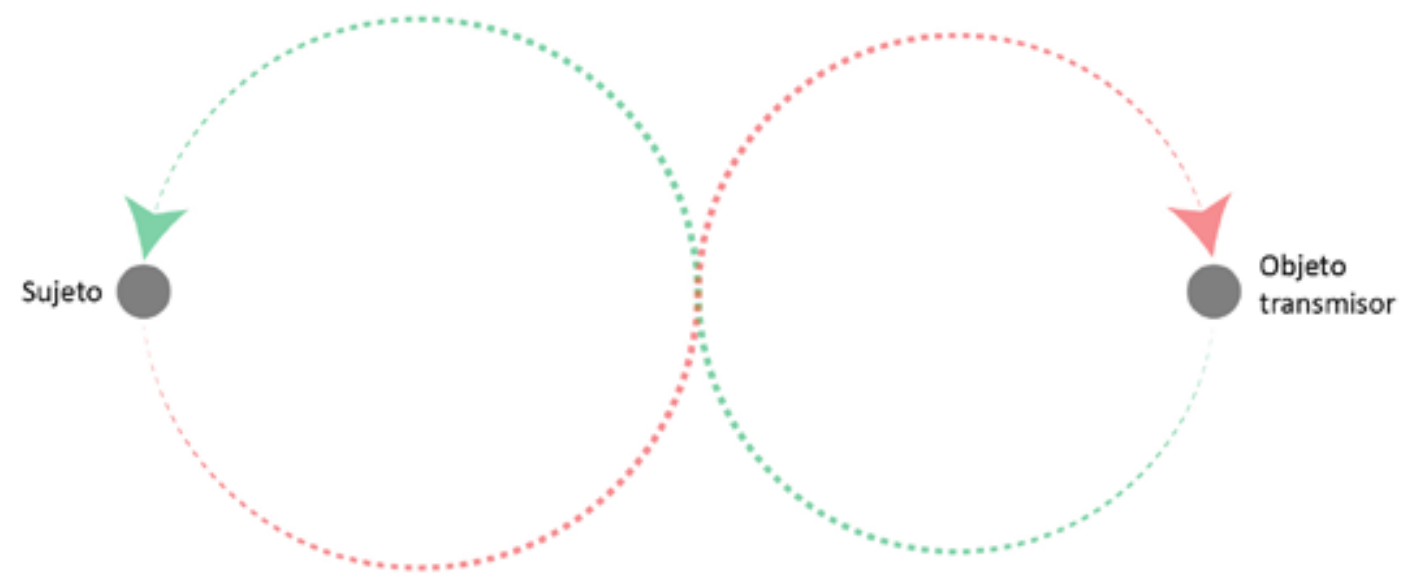

Figura 1-Ouroboros Mediático. Autor: Martin Kanek Gutiérrez

FENOMENOLOGÍA DE LA IMAGEN: ENTRE LOS OBJETOS Y LOS SUJETOS

La visión moderna de las imágenes.

A diferencia del concepto de habitar la imagen, tradicionalmente se ha entendido a ésta como representación y parte de un proceso unidireccional que tiene una fuente de origen, un transmisor, una señal, un mensaje, un receptor y un destino determinados. La imagen como representación estaría vinculada a un mensaje que contiene "bits" de información que da cuenta de aquello que nos rodea y podemos percibir.

Martin Heidegger (2010) menciona en La época de la imagen del mundo que la relación entre objeto y sujeto es definida en el modelo metafísico moderno que René Descartes desarrolló. Allí los sistemas de representación se constituyen como imagen que refleja lo que es externo (p 63-91). De esta manera se considera la piedra angular de esta metafísica moderna, la necesidad de "demostrar la realidad del mundo externo" (Heidegger, 2010: 80). El ser humano necesita generar modelos de representación para poder dar sentido y construir el mundo a partir de certezas sobre lo que se ha percibido, como parte de un acto tanto discursivo como racional. Se plantea que el mundo es percibido como un proceso de imágenes que se articulan en nuestra conciencia. En términos del autor, es "la reunión representadora de lo objetivo con el hombre representador dentro del círculo de la representabilidad garantizada por este" (Heidegger, 2010: 89).

La construcción racional sobre la imagen-mundo establece de manera ideal la relación entre el objeto y el sujeto. Lo ente es en la edad moderna un devenir del mundo en la medida que las certezas sobre él son parte de un proceso de cálculo racional. La imagen moderna desde la perspectiva de Heidegger es un conector que distancia al sujeto de lo observado, lo ente, al generar desde la investigación campos de objetos que se cuantifican y que están delimitados ontológicamente. De este modo el objeto de estudio de las ciencias modernas es lo ente a partir de la creación 
de representaciones por la calidad del sujeto de ser consciente de que tiene conciencia, poniendo a su disposición los elementos necesarios para identificar las propiedades y características propias de las cosas permitiéndole determinar certezas sobre aquello que es observado. En otras palabras, las certezas sobre la realidad parten de la construcción de la imagen-mundo.

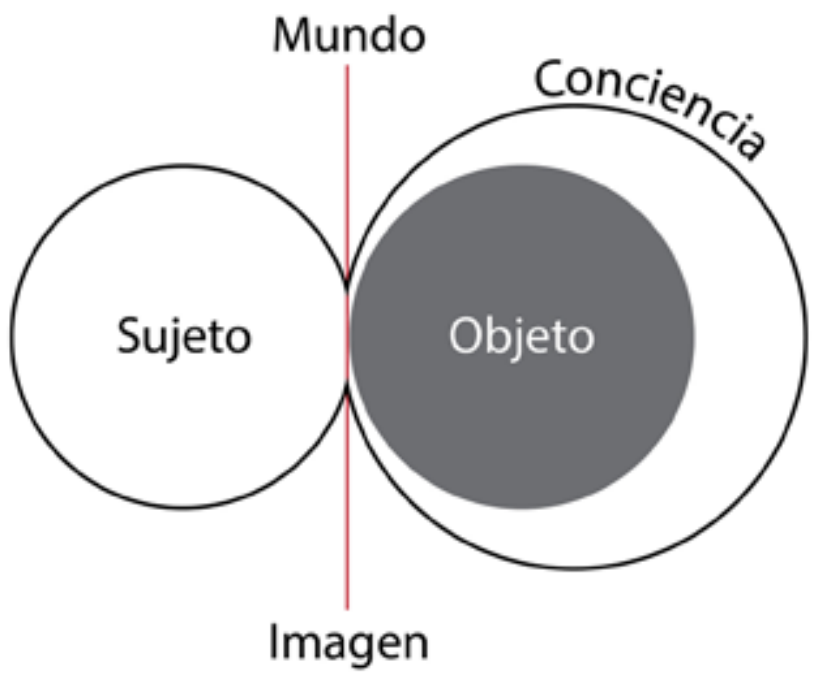

Figura 2-Imagen Mundo. Autor: Martin Kanek Gutiérrez

La relación entre sujeto (subjectum) y objeto (objectum) era distinta en la edad media. El subjectum no estaba relacionado con el yo, era más bien una esencia que estaba más allá de las cosas y se conservaba en el fondo de ellas (Vargas, 2005: 179). En la misma concepción el objectum era la presentación externa del subjectum que se ponía enfrente del individuo. En este sentido las cosas eran sujetos, de manera parecida a la última escena de la película La Grande Bellezza (2013) dirigida por Paolo Sorrentino en la que el protagonista sale a su balcón -con vista al Coliseo Romano- y ve a un grupo de flamencos que reposan de su largo viaje migratorio. En este instante el personaje llamado la Santa le indica al protagonista que ella sabe los nombres de pila de cada ave, sugiriendo de forma tácita que los pájaros descansan en ese lugar de manera consciente por familiaridad con la Santa y no por la vista del balcón. Sin mencionar dichos nombres el director plantea la necesidad del reencuentro con la dimensión de lo sagrado, dimensión que la taxonomía científica no alcanza a visibilizar como potencia de lo ente. Al referirnos a la imagen-mundo se establece que las palabras definen propiedades de los objetos que se pueden calcular e interpretar. El sujeto-objeto es entonces un cuerpo de propiedades singulares en el que se puede percibir lo subjetivo del objeto y la objetualidad intrínseca a los sujetos.

En la época actual es difícil percibir lo sustancial en los objetos sin una mediación en la que participe el yo, por causa de la interpretación de las palabras al nombrar las cosas como parte de un proceso subjetivo. En la película mencionada esto se refleja en que los nombres de los flamencos no se dicen, en beneficio de la faceta poética y mística que enmarcan la escena en un ambiente de sacralidad premoderna encarnada en el personaje de la Santa. Desde una perspectiva de lo tradicional en la imagen moderna se señala y configura una interpretación de lo percibido enmarcado en los elementos contenidos en el mundo de lo conocido.

\section{Las imágenes como entidades vivas.}

Merleau Ponty (1964) define en su libro Fenomenología de la Percepción que la relación entre sujetos y objetos desde la concepción moderna es "visible y móvil. Mi cuerpo está en el número de las cosas, es una de ellas, pertenece al tejido del mundo y su cohesión es el de una cosa" ( $p$ 17). Así, la experiencia diluye la distancia entre objeto y sujeto. Henri Bergson a su vez plantea que existe un plano inmanente en el que las imágenes lo son todo, integrando las ideas, las cosas y el mismo cerebro en una unidad

Vamos a fingir por un instante que no conocemos nada de las teorías de la materia y del espíritu, nada de las discusiones sobre la realidad o idealidad del mundo exterior. Heme aquí, pues, en presencia de imágenes, en el sentido más vago en que pueda tomarse esta palabra, imágenes percibidas cuando mis sentidos, inadvertidas cuando los cierro. Todas esas imágenes obran y reaccionan unas sobre otras en todas sus partes elementales según leyes constantes, que llamo las leyes de la naturaleza, y como la ciencia perfecta de esas leyes permitiría sin dudas calcular y prever lo que pasará en cada una de esas imágenes, el porvenir de las imágenes debe estar contenido en su presente y no añadirle nada nuevo. Sin embargo existe una de ellas que contrasta con todas las otras por el hecho de que no la conozco exclusivamente desde afuera por percepciones, sino también desde adentro por afecciones: es mi cuerpo (Bergson, 2006: 33).

A esta concepción se suma la postura de Gilles Deleuze manifestada en un curso impartido entre 1982 y 1983 en la Universidad Vincennes, proponiendo que todas las imágenes constituyen un plano del cual hace parte incluso el ojo de quien observa, como acontecimiento que sobre una pantalla enlaza las miradas con las imágenes proyectadas.

Cada uno de ustedes (dirigiéndose a los estudiantes) es una de esas imágenes en tanto no deja padecer acciones y efectuar reacciones. Vuestro ojo es una imagen en ese plano. Sufre acciones y tiene reacciones. ¿Vuestro cerebro? Sí, es una imagen. Entre paréntesis, no digan que tales imágenes se presentan a vuestro ojo... Vuestro ojo es una imagen en ese plano de inmanencia (Deleuze, 2014: 60).

El mundo visto en imágenes existe indistintamente del sujeto, por lo cual él por sí mismo no puede ser quien construye el mundo. En esto coinciden Bergson, Merleau-Ponty y Deleuze, más este último da relevancia a la experiencia como parte de la materialización de distintos procesos cognitivos que se enlazan en un sistema denominado "inmanente" de relaciones entre los sujetos y los objetos. La racionalidad pasa a ser entendida no sólo como una forma de enlazar palabras y construir discursos, sino como una experiencia: la experiencia de pensar. Este acto de pensar no es entonces el resultado de aquel principio en que la luz de la razón ilumina al ser y le permite trascender con el entendimiento a lo tangible y observable, cuyo resultado es la formación de las lenguas, la historia y hasta la misma concepción de Dios. El plano de la inmanencia (Deleuze, 2014: 60) 
propone que "el ser (...) es un flujo constante de devenir, o mejor, de devenires, de multiplicidades sin fin" (Ramírez, 2016: 196). Se entiende entonces que hay un conjunto de expresiones de las potencias de las cosas que se entrelazan conformando este gran plano en el que se materializa la realidad.

En la visión de Deleuze la subjetividad no responde a la identidad individual o a procesos propios de representación simbólica de la realidad. Es una postura vitalista que asume que hay una influencia que afecta y es afectada por una especie de "conciencia pre-reflexiva" (Zizek, 2006: 24). Como parte de la postura filosófica de Deleuze se propone lo pre-reflexivo como aquello que da cuenta de la existencia de zonas de indeterminación actuantes en ese plano de la inmanencia, gestando caóticamente transformaciones de manera infinita. Los límites no existen pues la determinación de algo restringe la posibilidad de multiplicidad del devenir. Al delimitar por ejemplo al "yo" se determinan sus posibilidades como sujeto constriñendo posibles vectores de la subjetividad, si ésta es entendida desde el cálculo como resultado de su definición. En este sentido podemos proponer como categoría de la mano de las imágenes-mundo: las imágenes-vivientes (ver Figura 3).
Todas las cosas u objetos existirían en un plano de inmanencia infinito, puesto que las imágenes -también inmanentes- interactúan entre sí configurando dicho plano. Un ejemplo de esto es el presente texto, cuya creación reproduce distintas imágenes como lo son los procesos mentales que articulan las palabras entre sí, la mirada puesta en el cursor, los oídos a la escucha de música por medio de audífonos, el contacto de los brazos con la mesa, la digitación del teclado por medio de los dedos de la mano... todas estas son imágenes que evocan una sensibilidad ante el conjunto de acciones que contiene el acto de escribir, cada una como un micro-acontecimiento vinculado con los demás. Son las reacciones de las acciones, las contracciones de los despliegues que se instalan en un tiempo que puede ser determinado o indeterminado. "El universo es uno y es el mismo en todas direcciones. La conciencia no es ser especial sino una imagen más, una imagen entre otras, al ras de todo lo existente" (Ramírez, 2016: 200-201). El acontecimiento se expresa en imágenes de sujetos y objetos que surgen de la oscilación entre las cosas en el plano de la inmanencia infinita.

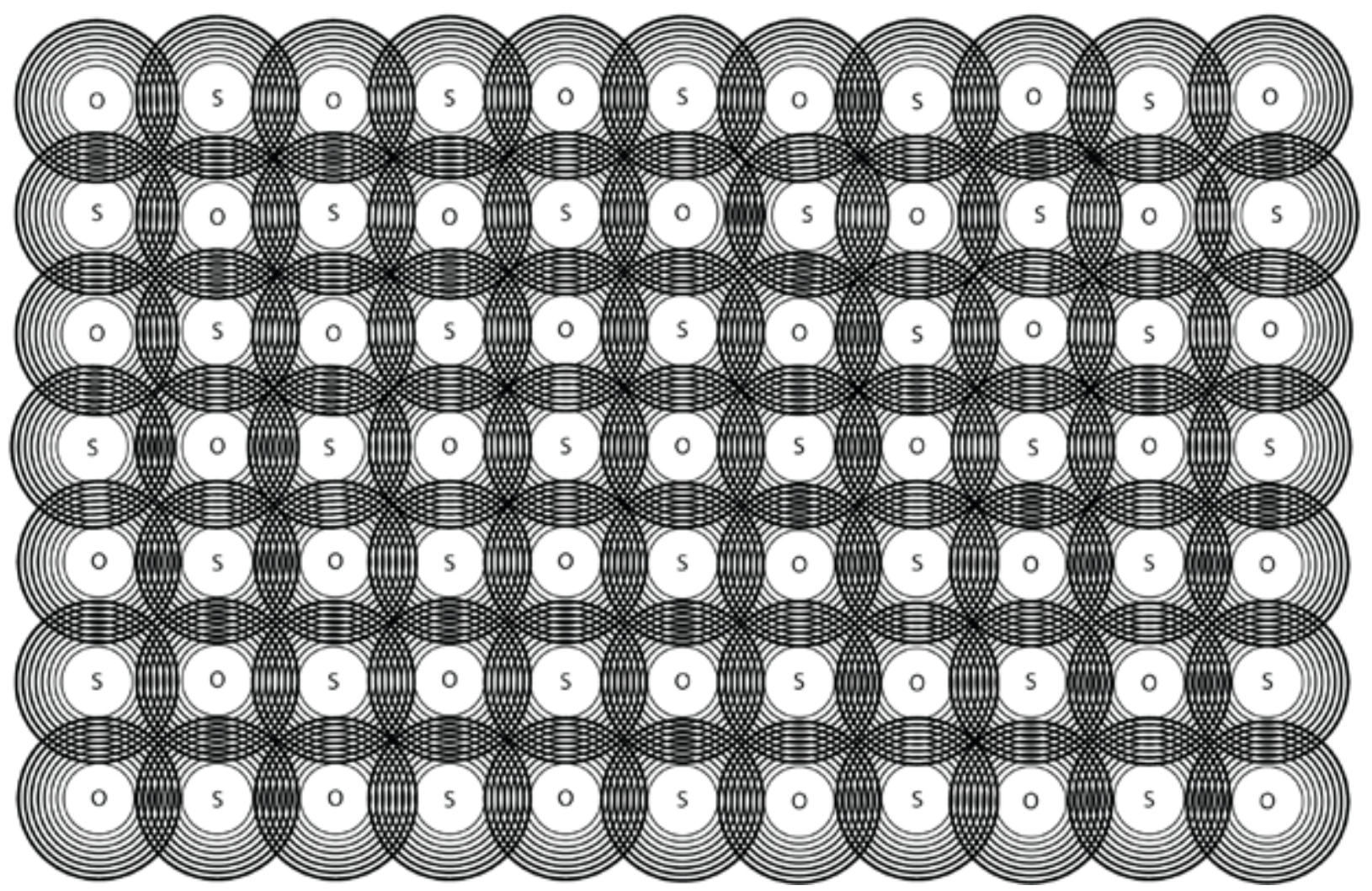

Figura 3-Diagrama de plano de inmanencia. Autor: Martin Kanek Gutiérrez

La ontología en la imagen.

En contraposición a las imágenes-mundo, que se encierran en sí mismas en representaciones donde sujetos y objetos se determinan -o sobredeterminan-, las imágenes-vivientes pertenecen al plano del infinito, son indeterminadas e incluso caóticas si retomamos a Deleuze. Ambas posturas ubican al sujeto desde su capacidad intelectual de interpretar la experiencia para construir su percepción de realidad. La subjetividad es entonces entendida como 
la serie de representaciones que a la vez son deterministas como oscilaciones resultado de la experiencia, es decir, la imagen racional contrapuesta con la imagen inmanente.

El Nuevo Realismo representado por Maurizzio Ferraris, Graham Harman, Quentin Meillassoux y Markus Gabriel plantea la ruptura ontológica en la interpretación del sujeto y el objeto, pues el segundo es independiente en un contexto de lo real con relación al primero. Se da un salto epistemológico del plano inmanente a una ontología plana (Harman, 2016a: 187) entendiendo que los objetos, las cosas, las imágenes, así como las ideas que los interpretan hacen parte de una misma dimensión o campo de lo que se considera la realidad. El enfoque del Nuevo Realismo es transversal a la presente investigación legando la concepción de la ontología de la imagen sin que ésta sea el eje central de las reflexiones filosóficas. En esta corriente, a grandes rasgos se plantea la posibilidad de que un sinnúmero de objetos puedan existir indistintamente de un sujeto, lo cual sugiere peligrosos cuestionamientos como: ¿podrían las imágenes existir sin sujetos? Incluso, ¿podrá existir subjetividad sin sujetos?.

Se resalta de manera especial la postura de Markus Gabriel quien concibe la relación dada entre los objetos sin estar enmarcada necesariamente en un esquema de interpretación cientificista y constructivista. Su propuesta radica en la existencia primero, de ámbitos objetuales y en segunda instancia, de campos de sentido.

Un AMBITO OBJETUAL es un área que contiene un determinado tipo de objetos y en la que se cumplen reglas que conectan estos objetos entre sí. Así sucede por ejemplo en el ámbito objetual de la política, que incluye a los votantes, los mítines, la llamada base de la política, los impuestos y muchas más cosas. También está el ámbito de los números naturales al que pertenecen por ejemplo el 7 y el 5 y en el que se cumplen ciertas leyes aritméticas básicas. Los ámbitos objetuales no están delimitados empero espacialmente (Gabriel, 2017: 31).

A su vez se puede ver a los campos de sentido como

(...) áreas en las que determinados aparecen de una manera determinada (...) No hay objetos o hechos fuera de los campos de sentido. Todo lo existente aparece en un campo de sentido (hablando estrictamente, en una infinidad de ellos). Existencia significa que algo aparece en un campo de sentido. Innumerables objetos aparecen en un campo de sentido sin que nadie se dé cuenta de ello en ningún momento. En el plano ontológico es indiferente que alguien lo perciba o no. Las cosas y los objetos aparecen no solo porque se nos aparezcan a nosotros, no solo existen porque nosotros las percibamos. La mayoría simplemente aparece, sin que nadie lo tenga en cuenta (Gabriel, 2017: 77-78).

En términos generales el autor propone que no hay necesidad de que haya un sujeto que por medio de su capacidad racional le otorgue sentido y propiedades a los objetos, sino que las cosas están determinadas por la existencia de campos de sentidos en los que emergen los llamados ámbitos objetuales. Las obras de arte por ejemplo dan paso al "reconocimiento de los objetos en sus contextos en lugar de aislarlos y tomarlos por cosas sin contrastes que simplemente existen por las buenas" (Gabriel, 2017, p. 200); el arte genera la posibilidad de que los objetos aparezcan en campos llenos de sentido gracias a las infinitas variables que emergen de cada contexto. Se distancia de la concepción de imagen-mundo pues se refiere a zonas ontológicas en las que se conforman los campos de sentido que tienen sus propios marcos lógicos de referencia, sus leyes, ensamblando los elementos que constituyen la existencia. La postura moderna implica que los procesos internos cognitivos de interpretación y verificación de la realidad del sujeto son los generadores de un sistema de relaciones que da legitimidad a la existencia del objeto, entre tanto que el Nuevo Realismo representado aquí por Markus Gabriel plantea que la delimitación y determinación de los campos de sentido no dependen del sujeto, son múltiples de por sí y no requieren de la presencia del sujeto para existir.

Pareciese que el yo como dimensión de la existencia despareciera en el Nuevo Realismo, como si el sujeto fuera un objeto más en algunos campos de sentido en las relaciones ontológicas, y que incluso los procesos internos de raciocinio se sumarán a los campos como un objeto más que pertenece al mismo plano que el del sujeto. Cabe aclarar que la pertenencia a un mismo plano no implica que por ejemplo, lo aquí escrito en palabras corresponda a una misma condición material que el teclado en el cual se escriben las palabras, ya que ni los sentidos ni los pensamientos determinan a esos objetos. Son diferentes puesto que las ideas, las sensaciones y el cuerpo como tal son objetos que interactúan con otros objetos en un entorno dado. Surge así una tercera categoría que podemos denominar imágenes ontológicas como una zona en la que los objetos interactúan.

\section{Habitando la imagen a través de la micro-inmanencia.}

Esta tercera categoría presenta dos tipos de imágenes: las imágenes-mundo y las imágenes-vivenciales. Se distinguen entre sí por el posicionamiento del sujeto al estar adentro, afuera o con los objetos. En esta relación las imágenes están supeditadas al sujeto por lo que son en sí mismas un puente o vínculo entre el mundo de lo trascendente con lo inmanente, como una imagen de tipo ontológico. Se constituye la dimensión en la que la imagen se habita a sí misma y donde el sujeto solo accede a ella por medio de una memorabilidad asentada en la impronta o huella que deja un evento. Se puede ver esta tensión en un ejemplo plasmado en la imagen que se presenta a continuación (Ver Figura 4) en el registro del texto, en un movimiento accidental que no tiene intencionalidad tras de sí y que se redactó en el marco del presente trabajo. La imagen per se existe sin necesidad de sujeto alguno como un acontecimiento en el plano de lo inmanente, sin sujeto que participe allí de su condición de ser. Nos preguntamos entonces, ¿Qué elementos hacen que se configuren las determinaciones de su duración? ¿Acaso alguno de los gatos lo hizo? ¿Fue $\mathrm{Baco}^{1}$ ? ¿Habrá sido un error del teclado del computador? La imagen que materialice un evento constituirá su respectiva representación aunque los orígenes que le dieron su expresión no necesariamente son conocidos por el escritor. Hay una falta de acceso a estas causas y sin embargo hay límites intrínsecos a cada evento que responden a las características del plano de la inmanencia. El devenir no presupone

Baco es el nombre de uno de los gatos que viven en casa del autor. 
lo infinito, más bien existen lo que se podría denominar "fracturas" en las que las experiencias están limitadas a las posibilidades, agotándose y resultando en dos opciones: sus transformaciones en una imagen representativa o el caer en el olvido. Una inmanencia que se descompone frente a lo ontológico, resultando en una especie de geografías óntico-experienciales que podemos entender como micro-inmanencias.

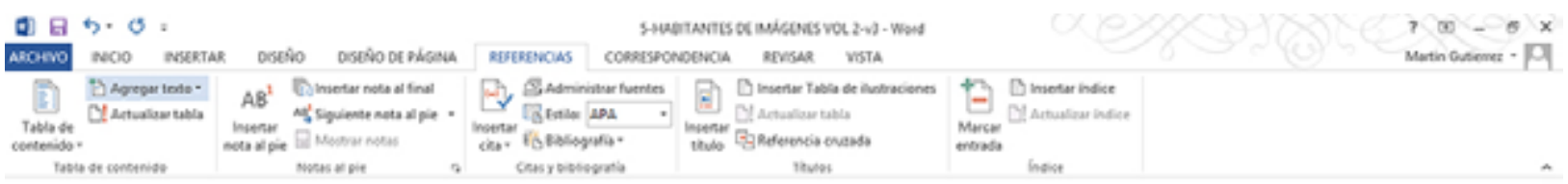

La postura filosófica del Nuevo Realismo plantea una ruptura ontológica en la relación sujetoobjeto, ya que los objetos son reales independientemente a la accesibilidad que el sujeto pueda tener con ellos. El plano de inmanencia se cambia por una ontologia plana001 (Harm11111111111111111111111111111111111111111111111111111111111an, 2016, p. 187), donde los objetos están sin la necesidad de una conciencia jerárquica que los catalogue. “

Las imágenes se vuelven rastros de las experiencias vividas del sujeto, ya sea en el mundo representado o en el plano de inmanencia. El Nuevo Realismo franquea de manera tangencial la presente investigación, dejando a su paso una noción de ontología de la imagen, aunque la imagen

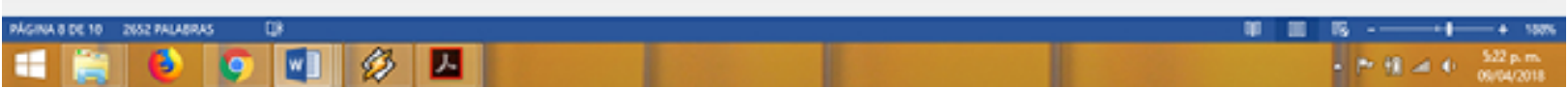

Para concluir el presente apartado se puede definir el habitar la imagen como una especie de tránsito que se desliza entre las imágenes-mundo, las imágenes-vivenciales y las imágenes-ontológicas en el que emergen de manera sucesiva diversos estadios micro-inmanentes. No se hace referencia a que se niegan las propiedades de las imágenes como mecanismos que representan a algo o a alguien, o que desaparezcan las imágenes entendidas como acontecimientos trascendentales. Se propone que cuando se habita la imagen se manifiesta un estado contemplativo en el que están articulados la experiencia y el símbolo, refiriendo incluso a la imagen de lo que no se ha visto. 


\section{LA MICRO-INMANENCIA EN EL RECUERDO Y LA MEMORIA}

Indagaremos en los fragmentos de la entrevista realizada a un artista colombiano, especializado en la instalación y realización de video. Fernando Domínguez Pérez nos habló de su experiencia y definición sobre la imagen y el cómo se habita la imagen durante el proceso creativo, los días 16 y 21 de noviembre del año 2017 . Se han codificado las referencias de acuerdo a las iniciales del nombre, su apellido, la herramienta utilizada y la ubicación de la información en la página de la entrevista realizada, así como el minuto en el video del registro de la misma. Este material constituye parte del archivo del trabajo de campo realizado para el proyecto "Habitantes de imágenes: una investigación poética entre la subjetividad y la imagen audiovisual".

Dos sub-categorías de las imágenes vivientes: inhalar y exhalar

El artista se cuestiona por las mutaciones del espacio y el tiempo, y cómo se pueden entender estas transformaciones, señalando que la imagen es un puente que vincula y conecta lo interno con lo externo, mediante los movimientos de inhalación y exhalación. Las imágenes se exhalan en cuanto el hábitat es inhalado. Lo externo se interioriza por parte del sujeto cuando éste inhala constituyéndose la imagen durante el proceso creativo. Las imágenes como producto de la capacidad que tenemos de habitar el entorno:

La imagen, nunca me había pensado una manera de definir la imagen. Se me ocurre la palabra apropiada... es como espiritual; la imagen es una introyección de una proyección que uno mismo hace. Es una inhalación y exhalación. El mundo es imagen, pero es imagen porque yo la exhalo como imagen, yo la hago imagen, yo la puedo ver, pero lo que veo está en mí... por eso es que te hablo de lo espiritual... Gandhi decía que el cambio que uno quiere ver en el mundo, lo tiene que hacer en uno mismo. ¡Ese es el habitar!, pero entonces uno lo puede entender en unos términos mucho más complejos que en un asunto ético (Fd.E1.p1-2).

El artista se alinea desde su concepción al concepto de imágenes-vivientes, en el sentido que le dan Bergson, Deleuze y Merleau-Ponty, sumándole la importancia del cuerpo de la imagen como un conector a partir de lo latente entre lo exterior y lo interior. Emergen así dos subcategorías de la imagen-viviente: la imagen-inhalación y la imagen-exhalación, como producto del proceso creativo de la imagen (ver Figura 5).

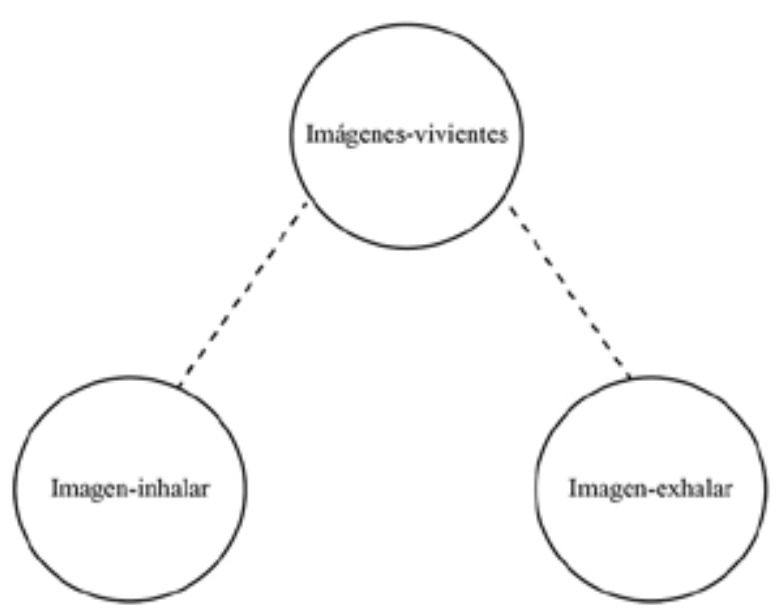

Figura 5-Diagrama de las imágenes vivientes. Autor: Martin Kanek Gutiérrez

Si las imágenes son oscilaciones entre lo interno y externo, las dos subcategorías definen que el devenir en el espacio tiempo corresponde al sistema de relaciones en el plano de la inmanencia. La "introyección-proyección" percibida por el artista evoca la noción de que la materia del cuerpo es una capa que hace parte de un complejo sistema en el que la interacción es el resultado de una experiencia que responde a una vibración dada entre sujetos y objetos. Las experiencias se manifiestan en un campo fenomenológico, en un espacio tiempo donde el sujeto las hace conscientes como parte de un proceso de aprendizaje en el que se perciben los objetos y lo cual es construido socialmente. Como resultado de la vibración se crea un espacio de la oscilación donde emergen formas de determinación que permite que la percepción produzca imágenes-mundo.

Dos sub-categorías de las imágenes ontológicas: imagen percibida e imagen oculta.

Avanzando en la entrevista y ahondando en el tema, algunas preguntas surgieron espontáneamente traspasando el umbral hacia fenómenos como el recuerdo y la memoria. Así, se quiso indagar por el primer recuerdo que tenía Fernando Domínguez.

Tenía 5 o $7 a^{a n ̃ o s}{ }^{2}$ y es la imagen de un sitio oscuro, una habitación a oscuras y en el piso un juguete que era un avión gordo que emitía luces de colores: rojos, azules y amarillos. Es una habitación de ángulos y creo que hay dos escritorios. Es una sensación de alegría por la sorpresa, pero también tiene algo de angustiante. No sé por qué, pero tiene un condimento de angustia.

Durante la entrevista la mamá de Fernando se interesó por lo conversado, y agregó que dicho juguete provenía de Argentina y era un regalo traído desde allí por familiares suyos. El enfoque de la investigación dio un giro al integrar por medio del recuerdo la imagen de la infancia a través de varios objetos, como lo son el avión "gordo", sus luces, la oscuridad circundante y los dos escritorios presentes en la escena. Se solicitó a la mamá del artista que facilitara una fotografía de la infancia del entrevistado donde se

La mamá del entrevistado intervino especificando que ese juguete era de Fernando cuando tenía 5 años. 
pudiera ver el avión gordo (ver Ilustración 1). Al observar la imagen que presentó la señora, el entrevistado indicó que ese avión no era el que él recordaba, a lo cual se suma que la imagen corresponde a otro tiempo -1985- en el que el artista tenía tan solo 2 años de edad.

Se puede resaltar que la importancia de la imagen -no necesariamente de la fotografía- subyace en que la acción de recordar evoca un evento o acontecimiento que revive emociones de otro tiempo relacionando varios objetos. Esto evidencia la presencia de imágenes-ontológicas en un plano oculto de las imágenes-vivientes y de las imágenes-mundo.

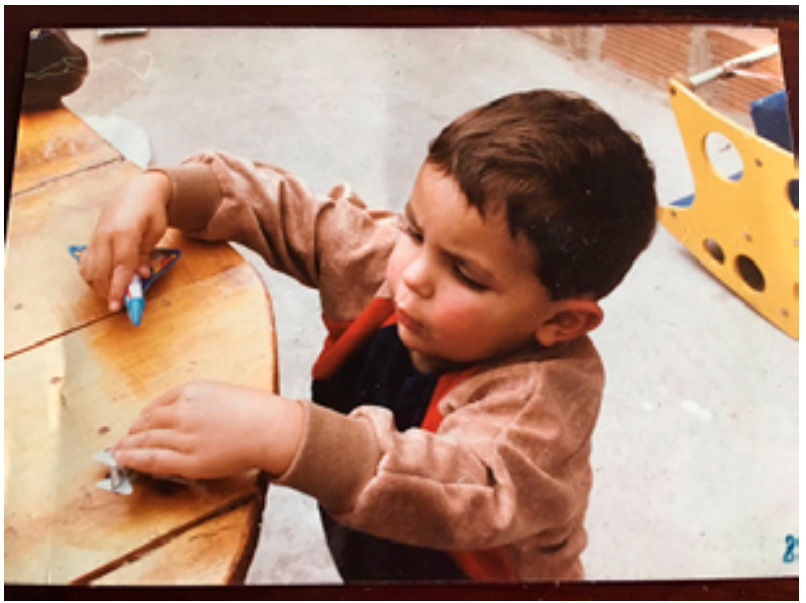

Ilustración 1- Fotografía de Fernando Domínguez. Cortesía Fernando Domínguez.

El análisis se establece en varios momentos. Primero, el fenómeno del adulto que recuerda en su niñez, a los 7 años, un juguete que alumbra con su luz la habitación. Segundo, la situación real del niño de 2 a 7 años que con una mezcla de emociones, entre alegría y angustia, observa el avión gordo cuyas luces rojas, azules y amarillas alumbran un cuarto oscuro donde hay dos escritorios. Se puede relacionar el primer fenómeno con las imágenes-mundo como un recuerdo en el que el sujeto representa a través del lenguaje una determinación de lo vivido y cómo se percibió, la imagen-mundo como una representación subjetivante que a partir de un acontecimiento produce un objeto. Ahora bien, el segundo fenómeno como imagen-viviente da cuenta del sujeto que en su infancia observó varios objetos en un espacio oscuro a manera de imagen-inhalación, en la que la impronta del evento queda marcada en el sujeto y su memoria, reproduciendo posteriormente una imagen que simbólicamente representa aquel momento de su niñez. Entonces la memoria estaría siendo configurada por las imágenes-vivientes desde los primeros años.

Un tercer fenómeno se evidencia a partir de la presencia de los objetos en el recuerdo. Los objetos existen por sí mismos y constituyen la imagen-ontológica en una dimensión extra-escópica, en la que el objeto está por fuera de la mirada, y sin embargo es lo que hace posible que la mirada pueda existir. La imagen-ontológica es la otra cara de la mirada, aquello que es visto aunque algunas de las propiedades y características reales del objeto permanecen ocultas. En palabras de Harman, "En general, los objetos se retiran a un ámbito sombrío y subterráneo que sostiene nuestra actividad consiente, sin hacerse notar de forma explícita” (2016b: 33).
La imagen-ontológica da volumen a lo observado. Así el objeto en su dimensión de creador de realidad permite plantear otras dos subcategorías: la imagen-percibida y la imagen-oculta (ver Figura 6). La primera refiere a aquello que conscientemente percibe el sujeto. La segunda es la que contiene aquellas cualidades que se mantienen ocultas aunque existen de por sí.

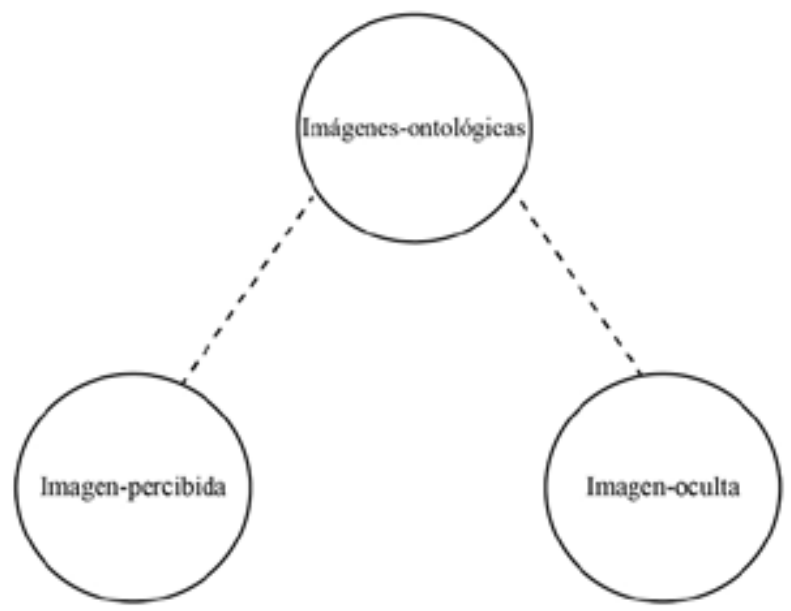

Figura 6-Diagrama de las imágenes ontológicas. Autor: Martin Kanek Gutiérrez

Las proporciones exactas de volumen y cualidad de los objetos en el caso del recuerdo de Fernando Domínguez son difíciles de saber, por lo que solo se obtendrán fragmentos y partes del evento, vacíos en la percepción que mantendrán ocultas algunas imágenes. Incluso accediendo a una fotografía de ese lapso de tiempo entre los 2 y 7 años del artista, estará oculta a la mirada y consciencia del sujeto parte de la realidad dada en ese acontecimiento específico. Incluso, el avión pudo ser gordo no por su cualidad intrínseca sino gracias a la adjudicación de esa característica por parte de Fernando en sus años de infancia.

Dos sub-categorías de las imágenes mundo: imagen propia e imagen cliché.

En el presente esquema de lógica sub-categorial habría que indagar por los referentes de las categorías emergentes en cuanto a las imágenes-mundo, culminando el análisis de la imagen como un espacio tiempo que se habita. Estas sub-categorías han sido referidas en la entrevista de forma indirecta, en el momento en que el artista recuerda momentos que son ajenos e inaccesibles para otros sujetos, pero que se expresan mediante el lenguaje verbal en la traducción que de la imagen hace el sujeto. La segunda ha sido referida a través de la experiencia de la búsqueda y visualización de la fotografía de la infancia de Fernando tomada del álbum familiar. La imagen de la foto permite que la memoria se configure a partir de los elementos estéticos presentes como lo son el mismo álbum, la fecha, los colores en tonalidad sepia relativos a una época, la impresión en papel de fotografía, representando lo que se supondría es la memoria sobre el evento. Esta imagen difiere de la imagen que Fernando construyó de un avión gordo evidenciando que lo que la fotografía registra no es necesariamente lo que la persona recuerda. En este contexto la imagen de la foto tiene un carácter cliché evocando 
aspectos generales del acontecimiento. Las categorías a plantear serían entonces, referentes a la existencia de una imagen-propia y una imagen-cliché.

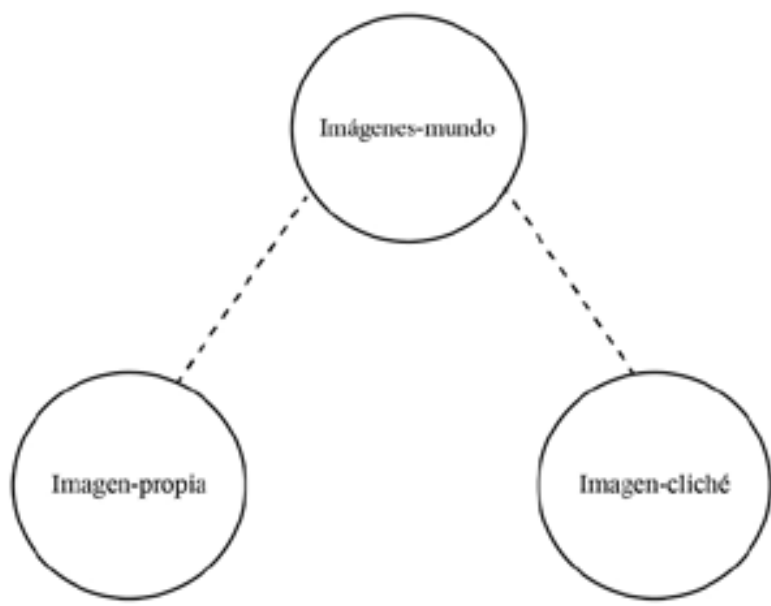

Figura 7-Diagrama de las imágenes mundo. Autor: Martin Kanek Gutiérrez

\section{CONCLUSIONES. LAS CATEgorías DE INTERPRETACIÓN DE LA IMAGEN COMO ESPACIO TIEMPO HABITADO}

La micro-inmanencia es a la vez habitar la imagen y habitar como imagen. Las tipologías de la imagen en su diversidad confluyen en el espacio del tiempo presente, dando a la capacidad de representación de la imagen nueve posibilidades diferentes, relativas a las categorías y subcategorías presentadas en este artículo. Hay tres categorías centrales: imágenes-mundo, imágenes-vivientes e imágenes-ontológicas que se descomponen gracias al análisis teórico y de la entrevista en cuatro subcategorías a saber: la imagen-inhalación y la imagen-exhalación como parte de las imágenes-vivientes, y, la imagen-percibida y la imagen-oculta como constitutivas de las imágenes-ontológicas. Por último nos encontramos con la imagen propia y la imagen cliché las cuales conforman a las imágenes-mundo (ver Figura. 8).

\section{Imágenes-vivientes}

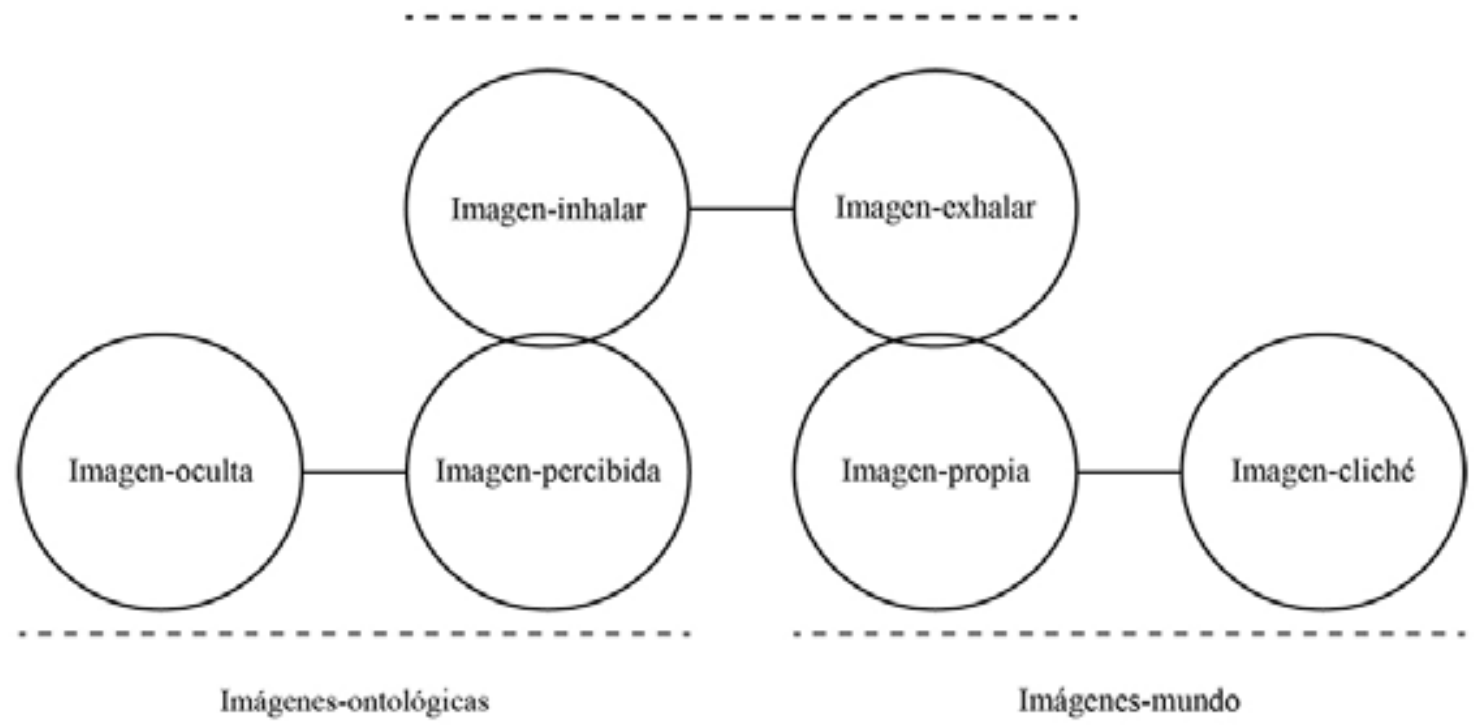

Figura 8-Diagrama total de las imágenes. Autor: Martin Kanek Gutiérrez 
Las seis sub-categorías constituyen un esquema completo representado en el diagrama, ilustrando cómo se constituye la realidad a través de la imagen a partir de las tres categorías principales, sus subcategorías respectivas y la relación de cercanía y distancia entre ellas. Se cristaliza al objeto mediante el registro fotográfico volviéndolo un cliché, entre tanto que la experiencia le da forma al objeto por medio del lenguaje. La imagen-percibida perteneciente a las imágenes-ontológicas está vinculada y entrelazada con la imagen-inhalada, y por su parte la imagen-propia se enlaza con la imagen-exhalada. Así, registrar las imágenes-vivientes se convierte en un punto de encuentro entre lo trascendente del cliché y lo infrascendente de la ontología.
Habitar la imagen es un acto que implica un movimiento en el espacio y a través del tiempo, configurando una micro-inmanencia en la relación que se da entre los tres fenómenos. La experiencia evoca una representación de lo visto y lo vivido en un trasegar entre lo oculto y lo percibido, objetos articulados por quiebres ontológicos. La micro-inmanencia puede ser entendida como una geografía de las transformaciones ontológicas en la que objetos y acontecimientos llevan al sujeto a habitar la imagen produciendo planos singulares en medio de la multiplicidad de las posibilidades (ver Figura 9 y 10). Es el punto o lugar de encuentro entre lo finito con lo infinito. Para el caso del avión gordo hay una delimitación objetual ontológica con el recuerdo de la presencia de mesas, luces de colores, los ángulos del cuarto y el infante observando. Más allá del recuerdo, el acontecimiento en sí genera la posibilidad de que nuevas imágenes sean percibidas y posteriormente representadas.
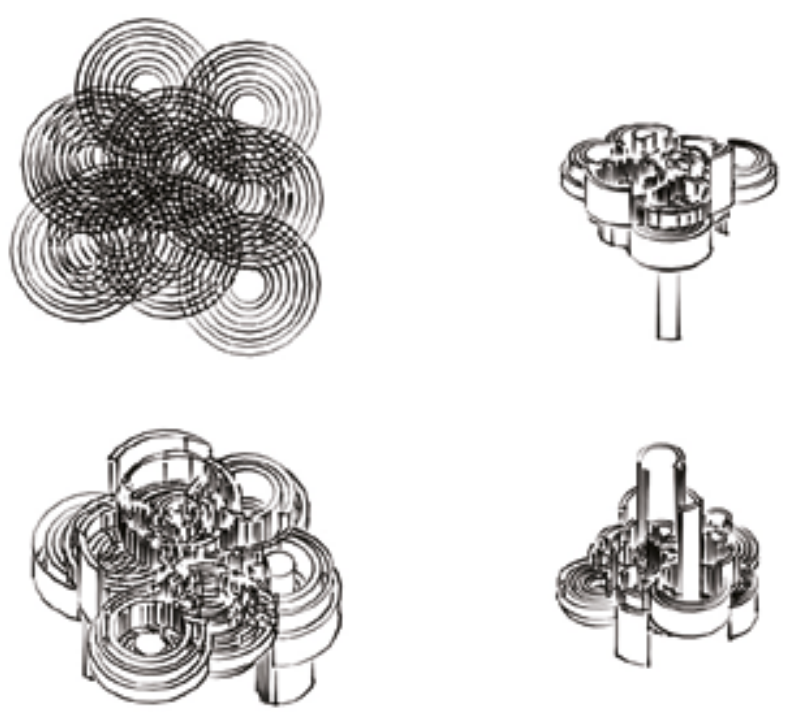

Figura 9-Diagramaen 3d de una micro-inmanencias. ${ }^{3}$ Autor: Martin Kanek Gutiérrez

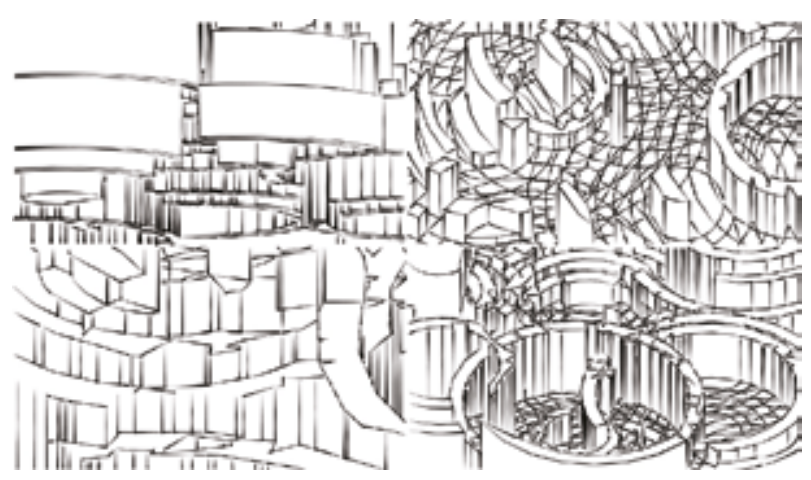

Figura 10-Diagrama en 3d del interior de una micro-inmanencias. Autor: Martin Kanek Gutiérrez
El diseño de este diagrama consistió en representar, a través del dibujo, un sistema de oscilaciones de cirulos concéntricos que se yuxtaponen, creando una geometría caótica. Después se trabajó en un software de 3 d que permitió hacer la extrusión de sus superficies imitando las fracturas de una posible geografía imaginaria que configuren una primera imagen-mundo de una micro-inmanencia. 


\section{REFERENCIAS}

BERgSON, H. (2013). Materia y Memoria. Ensayo sobre la relación del cuerpo con el espíritu. Buenos Aires: Cactus.

Deleuze, G. (2014). Cine I/ Los signos del movimiento y el tiempo. Buenos Aires: Cactus.

Domínguez, F. (2016). Cronografías. Video instalación. Ver en: http://ivahm.com/ portfolio/fernando-dominguez-cronografias/

GABriel, M. (2014). Porque el mundo no existe. Barcelona: Pasado \& Presente.

GutiÉRrez, M. (2017). Los habitantes de imágenes: entre la subjetividad y la imagen audiovisual. En: Estuarios entre la comunicación y el diseño. Campuzano, C., Plaza J., Freites T. (pp. 107-116). Bogotá: CUN editorial.

Harman, H. (2016A). El camino de los objetos. En: El nuevo realismo: la nueva filosofía del siglo XXI. Ramírez, M. Ed. (pp. 11-45). Ciudad de México: Siglo XXI editores.

HARmAn, H. (2016B). El objeto cuádruple. México: Anthropos.

Heidegger, M. (2010). La época de la imagen del mundo. En: Caminos del bosque (pp. 63-90). Madrid: Alianza editorial.

MÁRQUEZ, I. (2015) Una genealogía de la pantalla. Barcelona: Anagrama.

Merleau-Ponty, M. (1986) El ojo y el espíritu. Barcelona: Paidós.

Ramírez, M. (2016) Presentación del nuevo realismo. En: El nuevo realismo: la nueva filosofía del siglo XXI. Ramírez, M. Ed. (pp. 11-45). Ciudad de México: Siglo XXI editores.

Zızek, S. (2006) Órganos sin cuerpos: sobre Deleuze y consecuencias. Valencia: Pre-Textos.

Bergson, H. (2013) Materia y Memoria. Ensayo sobre la relación del cuerpo con el espíritu. Buenos Aires: Cactus.

GutiéRrez, M. (2016-2017) Habitantes de imágenes: una investigación poética entre la subjetividad y la imagen audiovisual. Diarios de campo.

\section{FiLMOgRAFÍA CITADA}

Sorrentino, P. (2013) La grande belleza. Italia: Medusa Film. 